\title{
Hemoglobin (Hb) Val de Marne (Hb Footscray) in Brazil: the first case report
}

\author{
J.V. Okumura ${ }^{1}$, E.L.T. Shimauti ${ }^{2}$, D.G.H. Silva ${ }^{1}$, L.S. Torres ${ }^{1}$, \\ E. Belini-Junior ${ }^{1}$, R.G. Oliveira ${ }^{1}$, E.V. Patussi ${ }^{2}$, J.C.M. Herrero ${ }^{2}$ and \\ C.R. Bonini-Domingos ${ }^{1}$ \\ ${ }^{1}$ Laboratório de Hemoglobinas e Genética das Doenças Hematológicas, \\ Departamento de Biologia, Universidade Estadual Paulista, \\ São José do Rio Preto, SP, Brasil \\ ${ }^{2}$ Laboratório de Ensino e Pesquisa em Análises Clínicas, \\ Departamento de Análises Clínicas e Biomedicina, \\ Universidade Estadual de Maringá, Maringá, PR, Brasil \\ Corresponding author: J.V. Okumura \\ E-mail: jessika_okumura@hotmail.com
}

Genet. Mol. Res. 15 (2): gmr.15028294

Received December 16, 2015

Accepted February 11, 2016

Published July 15, 2016

DOI http://dx.doi.org/10.4238/gmr.15028294

\begin{abstract}
Hemoglobin $(\mathrm{Hb})$ variants involving alpha-chains are less common in the global population than $\mathrm{Hb}$ variants resulting from beta-chain alterations. Generally, alpha-chain $\mathrm{Hb}$ variants are caused by point mutations affecting alpha-1 and/or alpha-2 genes of the alpha-globin cluster (HBA1 and $H B A 2)$. In Brazil, the most prevalent alpha-chain $\mathrm{Hb}$ variant is $\mathrm{Hb}$ Hasharon. In this study, we present the first case of an $\mathrm{Hb}$ Val de Marne variant in the Americas, specifically in Brazil.
\end{abstract}

Key words: Hemoglobin variants; Alpha-globin; HPLC 


\section{INTRODUCTION}

Hemoglobin $(\mathrm{Hb})$ variants are generally characterized by point mutations in globin genes, mainly in alpha- and beta-globin genes ( $H B A$ and $H B B$ ) modifying the formation of alpha- and beta-globin chains (Clarke and Higgins, 2000; Weatherall and Clegg, 2001). Owing to damaged tetrameric structure, the globins can form molecules with altered function; however, many mutations do not cause severe functional alterations, and the carriers are asymptomatic (Clarke and Higgins, 2000).

Of the $1218 \mathrm{Hb}$ variants described, 587 result from mutations in the beta-globin cluster and 464 from mutations in the alpha-globin cluster. Regarding the point mutations (a change of a single nitrogenous base), 326 are related to beta-globin genes and 196 to alphaglobin genes (Globin Gene Server; http://globin.cse.psu.edu/). The most common Hb variants, both in Brazil and globally, are those that affect the beta gene $(H B B)$, namely $\mathrm{Hb} \mathrm{S}, \mathrm{Hb} \mathrm{C}$, and $\mathrm{Hb} \mathrm{D}$ (Weatherall and Clegg, 2001). The Hb variants resulting from changes in the alpha gene $(H B A)$ are less frequent, and can be confused with other $\mathrm{Hb}$ variants during laboratory diagnosis. The most prevalent variant in Brazil is $\mathrm{Hb}$ Hasharon, followed by $\mathrm{Hb}$ Stanleyville II and Hb J-Rovigo (Kimura et al., 2015).

$\mathrm{The} \mathrm{Hb}$ variant described in the present study, $\mathrm{Hb}$ Val de Marne (also known as $\mathrm{Hb}$ Footscray), is caused by replacement of the nitrogenous base cytosine by adenine at the 34th codon of the third exon of alpha-globin genes 1 or 2 (HBA1 or HBA2), promoting exchange in the synthesized polypeptide chain of the amino acid serine (codon AGC) for arginine (codon AGA) at position 133 (HBA:p.Ser133Arg) (Wajcman et al., 1993; Owen and Hendy, 1994; Ma et al., 2004; Akbari and Hamid, 2012). Val de Marne is a rare $\mathrm{Hb}$ variant and has been described in only four families throughout the world, the first report being in 1993 in France (Wajcman et al., 1993), followed by Australia (Owen and Hendy, 1994), China (Ma et al., 2004), and Iran (Akbari and Hamid, 2012). The terms $\mathrm{Hb}$ Val de Marne (Hb VM) and $\mathrm{Hb}$ Footscray derive from the regions where this variant was first described.

We present here the first report of the $\mathrm{Hb}$ variant Val de Marne in the Brazilian population, and the first results of laboratory tests for $\mathrm{Hb}$ variants available in Brazil.

\section{MATERIAL AND METHODS}

\section{Case}

The subject of the case (L.T.M.) is a blood donor at the Regional Hemocenter of Maringá-PR, in the southern region of Brazil. L.T.M. is a 32-year-old Brazilian woman of Italian and Ukrainian ancestry. She lives a healthy life without any medical complaints and has no family history of anemia. As a preliminary analysis, the blood sample was subjected to hemoglobin electrophoresis at $\mathrm{pH} 8.6$ and $\mathrm{pH}$ 6.2, a sickle test, and a complete blood count. However, the diagnosis for this sample was inconclusive.

\section{Hemoglobin electrophoresis at pH 8.6 (Marengo-Rowe, 1965)}

We used this qualitative technique for the detection of normal and abnormal $\mathrm{Hb}$. The interpretation is based on different $\mathrm{Hb}$ electrical charges, which lead to different electrophoretic mobilities of the normal $\mathrm{Hb}$. The running buffer used was Tris-EDTA-borate at $\mathrm{pH} 8.6$ 
(Tris(hydroxymethyl)aminomethane) (Tris), $10.2 \mathrm{~g} / \mathrm{L}(0.0842 \mathrm{M})$; ethylenediaminetetraacetic acid (EDTA), 0.6 g/L (0.002 M); boric acid, $3.2 \mathrm{~g} / \mathrm{L}(0.0517 \mathrm{M})$ ), and the hemolyzed sample was applied on cellulose acetate tapes as substrates.

\section{Hemoglobin electrophoresis at pH 6.2 (Vella, 1968)}

We used this qualitative technique to differentiate between $\mathrm{Hb}$ that migrate to similar positions such as $\mathrm{Hb} \mathrm{S}$ and $\mathrm{C}$ under electrophoresis at alkaline $\mathrm{pH}$. The running buffer used was sodium phosphate at $\mathrm{pH} 6.2\left[\mathrm{Na}_{2} \mathrm{HPO}_{4}, 2.02 \mathrm{~g} / \mathrm{L}(0.0142 \mathrm{M})\right.$ and $\mathrm{NaH}_{2} \mathrm{PO}_{4} \cdot \mathrm{H}_{2} \mathrm{O}, 7.66 \mathrm{~g} / \mathrm{L}$ $(0.0555 \mathrm{M})]$ and the hemolyzed sample was applied on agar-agar gel as substrate (1 g agar: 5 $\mathrm{mL}$ sodium phosphate buffer).

\section{Polypeptide chains electrophoresis at pH 8.6 (Schneider, 1974)}

We used this technique to identify normal and altered globin chains. The running buffer used was Tris-EDTA-borate at $\mathrm{pH} 8.6(70 \mathrm{~mL})$ with urea $(36 \mathrm{~g}, 8562 \mathrm{M})$ and 2-mercaptoethanol $\left(\mathrm{C}_{2} \mathrm{H}_{6} \mathrm{OS}, 6.4 \mathrm{~mL}, 1.17 \mathrm{M}\right)$. The hemolyzed sample was applied on cellulose acetate tapes as substrates.

\section{Hemoglobin separation and quantification by high-performance liquid chromatography (HPLC)}

Based on the ionic charge of each $\mathrm{Hb}$ fraction it is possible to identify the $\mathrm{Hb}$ profile and the percentage values of each fraction. We used VARIANT ${ }^{\mathrm{TM}}$ system (Bio-Rad Laboratories, Hercules, CA, USA) with an heterozygous beta thalassemia assay kit and Ultra2 Resolution system (Trinity Biotech, Wicklow, Ireland) with Genesys assay kit.

\section{Hematological tests}

The erythrocyte parameters were obtained using an Auto Hematology Analyzer, BC300 PLUS (Mindray, China). Microscopic analysis of erythrocytes was performed using blood smears colored by May-Grünwald-Giemsa staining and visualized using a light microscope at 40X magnification.

\section{RESULTS}

The hematologic data did not reveal any alterations, except mild elevation in the red blood cell distribution width coefficient of variation (RDW-CV), indicating slight anisocytosis (Table 1). The data show that L.T.M. did not present anemia, erythrocytosis, or any relevant qualitative abnormalities in erythrocytes.

The electrophoretic migration pattern of the $\mathrm{Hb} \mathrm{VM}$ observed at $\mathrm{pH} 8.6$ occurred between the $\mathrm{Hb} \mathrm{A}$ and $\mathrm{Hb} \mathrm{S}$ positions (Figure 1A). In the electrophoresis at $\mathrm{pH}$ 6.2, this variant migrated discretely below the $\mathrm{Hb} \mathrm{S}$ position (Figure 1B). The altered fraction of the alphachain $\left(\alpha^{\mathrm{M}}\right)$ was observed in the polypeptide chain electrophoresis at $\mathrm{pH} 8.6$ (Figure 1C). 
Table 1. Hematological parameters for L.T.M. and reference values.

\begin{tabular}{l|c|c}
\hline Hematological parameters & Values & Reference values \\
\hline Erythrocyte $\left(\mathrm{x} \mathrm{10} 10^{12} / \mathrm{L}\right)$ & 4.83 & $4.0-5.4$ \\
\hline Hemoglobin $(\mathrm{g} / \mathrm{dL})$ & 13.4 & $36-16$ \\
\hline Hematocrit $(\%)$ & 42.0 & $80-96$ \\
\hline MCV (fL) & 86.9 & $27-32$ \\
\hline MCH (pg) & 27.7 & $32-36$ \\
\hline MCHC (\%) & 31.9 & $13.0-15.3$ \\
\hline RDW-CV (\%) & 15.5 & \\
\hline
\end{tabular}

$\mathrm{MCV}=$ mean corpuscular volume; $\mathrm{MCH}=$ mean corpuscular hemoglobin; $\mathrm{MCHC}=$ mean corpuscular hemoglobin concentration; RDW-CV $=$ red cell distribution width-coefficient of variation.
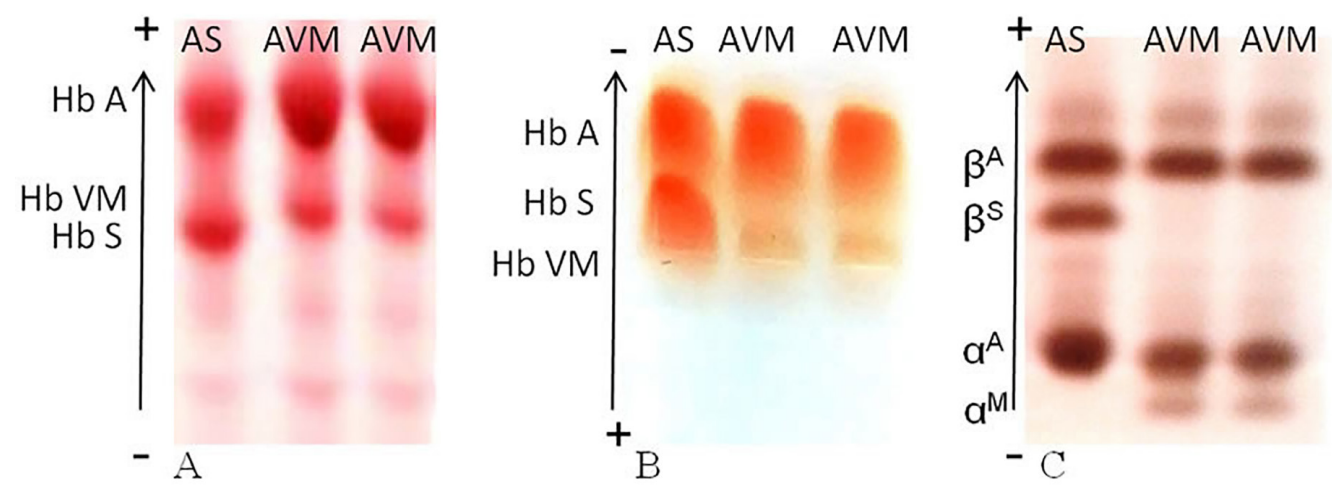

Figure 1. Electrophoretic mobility of hemoglobin $(\mathrm{Hb})$ variant Val de Marne compared with $\mathrm{Hb}$ S. A. Electrophoresis at $\mathrm{pH} 8.6$ on cellulose acetate tape. B. Electrophoresis at $\mathrm{pH} 6.2$ on agar-agar gel. C. Polypeptide chain electrophoresis at $\mathrm{pH} 8.6$ on cellulose acetate tape. Each picture depicts three samples: the first is a standard sample heterozygous for $\mathrm{Hb} \mathrm{S}(\mathrm{Hb} \mathrm{AS})$; the second and third are heterozygous for $\mathrm{Hb}$ Val de Marne (AVM). The arrows indicate the electrophoretic run direction.

The $\mathrm{Hb} \mathrm{VM}$ chromatographic profile was similar in both HPLC systems presenting a retention time that was longer than for $\mathrm{Hb} \mathrm{A}$. Using the Ultra2 Resolution system (Trinity Biotech), the $\mathrm{Hb} \mathrm{VM}$ was eluted at the relative retention time of $\mathrm{S}(0.98)$ with $13.4 \%$ concentration. We also observed a hybrid form of $\mathrm{Hb} \mathrm{VM}$, denominated $\mathrm{Hb}$ Val de Marne 2 ( $\mathrm{Hb} \mathrm{VM} 2$ ), at retention time $\mathrm{S}(1.07)$ with $0.6 \%$ concentration (Figure $2 \mathrm{~A})$. This pattern was compatible with the chromatogram of the Trinity Biotech variant library (Figure $2 \mathrm{C}$ ). In the VARIANT $^{\mathrm{TM}}$ system (Bio-Rad), the $\mathrm{Hb} \mathrm{VM}$ appeared in the same window of $\mathrm{Hb} \mathrm{S}$ elution with retention time of 4.41 and $14.7 \%$ concentration. The Hb VM2 appeared in an unknown window with retention time of 4.63 and $0.9 \%$ concentration (Figure $2 \mathrm{~B}$ ).

Regarding the concentration of the other $\mathrm{Hbs}$, in the chromatogram using the Ultra2 Resolution system, the $\mathrm{Hb}$ A concentration was $66.8 \%$, the $\mathrm{Hb} \mathrm{A}_{2}$ concentration was $1.8 \%$, and the $\mathrm{Hb} \mathrm{F}$ concentration was $0.0 \%$. In the chromatogram performed using the VARIANT ${ }^{\mathrm{TM}}$ system, the $\mathrm{Hb} \mathrm{A}$ concentration was $74.5 \%$, the $\mathrm{Hb} \mathrm{A}_{2}$ concentration was $2.6 \%$, and the $\mathrm{Hb} \mathrm{F}$ concentration was $0.0 \%$. 


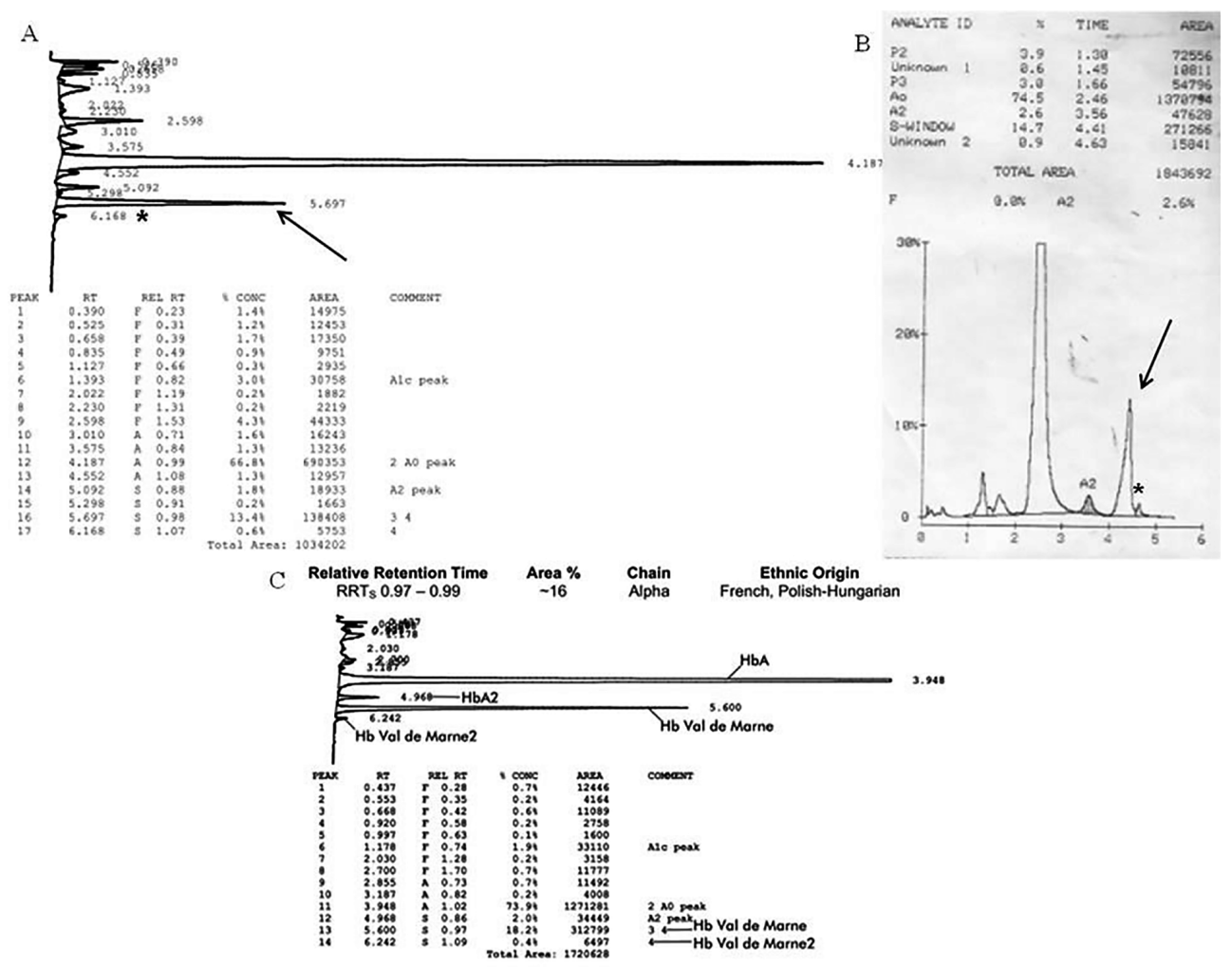

Figure 2. Chromatographic profile of hemoglobin $(\mathrm{Hb}) \mathrm{A} / \mathrm{Val}$ de Marne. A. Chromatogram performed using the Ultra2 Resolution system (Trinity Biotech). The Hb Val de Marne 1 peak appeared with $13.4 \%$ concentration at a relative retention time for $\mathrm{S}(\mathrm{RRT} / \mathrm{S})$ of 0.98 . The $\mathrm{Hb}$ Val de Marne 2 peak appeared with $0.6 \%$ concentration at an RRT/S of 1.07. B. Chromatogram performed using a VARIANT ${ }^{\mathrm{TM}}$ system (Bio-Rad). The Hb Val de Marne 1 peak appeared in the elution window of $\mathrm{Hb} \mathrm{S} \mathrm{(4.41)} \mathrm{with} \mathrm{14.7 \%} \mathrm{concentration} \mathrm{and} \mathrm{the} \mathrm{Hb}$ Val de Marne 2 appeared in an unknown window with a retention time of 4.63 with $0.9 \%$ concentration. C. Chromatographic profile found in variant library made available by Trinity Biotech. The arrows indicate the $\mathrm{Hb}$ Val de Marne 1 peak and the asterisks indicate the $\mathrm{Hb}$ Val de Marne 2 peak.

\section{DISCUSSION}

The present study provides the first description of $\mathrm{Hb}$ Val de Marne in the American continent, more specifically in Brazil. The analysis of the hemoglobins and polypeptide chains in the electrophoretic profiles under different $\mathrm{pH}$ conditions, and the chromatographic profiles presented by the sample, allowed us to identify $\mathrm{Hb}$ Val de Marne and compare the results with other studies that have indicated this $\mathrm{Hb}$ variant in other populations (Wajcman et al., 1993; Owen and Hendy, 1994; Ma et al., 2004; Akbari and Hamid, 2012).

Wajcman et al. (1993) first described the Hb VM variant in a French family during a neonatal hemoglobinopathy screening program. The family resides in the Val de Marne Department situated to the southeast of Paris. In 1994, the same Hb variant was described by Owen and Hendy (1994) as a new $\mathrm{Hb}$ variant denominated $\mathrm{Hb}$ Footscray (owing to the region of Australia where it was discovered). 
The description of the Footscray variant as a new $\mathrm{Hb}$ occurred because of the different patterns visualized in isoelectrofocusing (IEF), alkaline and acidic electrophoresis, and ion-exchange HPLC (Wajcman et al., 1993). Two newborns with alpha-chain Hb variants presenting IEF results with a slower migration pattern than $\mathrm{Hb} F$ were identified in the Department of Val de Marne. The parents of the children were examined and both the fathers, who were brothers, showed the same Hb pattern. One, a 39-year-old man, was investigated more closely. His red blood cell parameters were normal. Alkaline electrophoresis at $\mathrm{pH}$ 8.6 verified that the $\mathrm{Hb} \mathrm{VM}$ migrated as two bands, one being more evident and formed by two mutated alpha-chains and two normal beta-chains $\left(\alpha_{2}{ }^{\mathrm{M}} / \beta_{2}{ }^{\mathrm{A}}\right)$, and the other less evident and formed by a hybrid (Hb VM2) of one normal alpha-chain with one mutated alpha-chain and two normal beta-chains $\left(\alpha^{\mathrm{A}} \alpha^{\mathrm{M}} / \beta_{2}{ }^{\mathrm{A}}\right)$. In citrate-agar electrophoresis at $\mathrm{pH} 6.0$, the $\mathrm{Hb}$ VM migrated below $\mathrm{Hb} \mathrm{A}$. The $\mathrm{Hb} \mathrm{VM}$ concentration in this patient was $16.0 \%$, the $\mathrm{Hb}$ $\mathrm{A}_{2}$ concentration was $2.7 \%$, and the $\mathrm{Hb} \mathrm{F}$ concentration was $0.5 \%$. The oxygen-binding properties verified that $\mathrm{Hb} \mathrm{VM}$ presented a 1.7-fold increase in oxygen affinity (Wajcman et al., 1993). The same pattern described above was verified in a healthy 27 -year-old male of Polish-Hungarian descent. The Hb VM concentration was 15.0\% of the total Hb (Owen and Hendy, 1994).

Ma et al. (2004) presented the molecular characterization of a point mutation that comprised the substitution of a cytosine by an adenine in codon 34 of the $H B A 1$ or $H B A 2$ genes (AGC $>$ AGA) causing the replacement of amino acid 133 in the protein (HBA:p.Ser133Arg). They found this mutation by automated DNA sequencing in a 15 -year-old Chinese girl and her 61-year-old father, both without anemia. The pattern of $\mathrm{Hb}$ was determined by HPLC using a VARIANT II ${ }^{\mathrm{TM}} \mathrm{Hb}$ Testing System (Bio-Rad Laboratories, Hercules, CA, USA) using the beta-thalassemia Short Program, and they found an $\mathrm{Hb}$ variant at the $\mathrm{Hb} \mathrm{S}$ window with a concentration of $14.4 \%, \mathrm{Hb} F$ with a concentration of $<0.1 \%$, and $\mathrm{Hb} \mathrm{A}_{2}$ with a concentration of $1.7 \%$ for the girl. The same $\mathrm{Hb}$ variant with a concentration of $16.0 \%$ was verified in the father's blood sample. The last report of the $\mathrm{Hb} \mathrm{VM}$ variant was in a 26-year-old man living in Iran. Unlike in the other reports in which individuals had only one alpha gene altered, this man presented the heterozygous variant, or two abnormal $H B A$ genes, with a percentage of $\mathrm{Hb}$ VM of 35.9\% (Akbari and Hamid, 2012).

In the present case report, during alkaline electrophoresis, the $\mathrm{Hb} \mathrm{VM}$ variant migrated between $\mathrm{Hb} \mathrm{A}$ and $\mathrm{Hb} \mathrm{S}$, and it was not possible to detect the hybrid (Hb VM2), probably owing to its low concentration. During the agar-agar electrophoresis, the $\mathrm{Hb} \mathrm{VM}$ variant migrated below $\mathrm{Hb} \mathrm{S}$. Both electrophoresis results suggest an $\mathrm{S}$-like Hb variant. Therefore, we electrophoresed polypeptide chains at $\mathrm{pH} 8.6$ and confirmed that the $\mathrm{Hb}$ variant was an alpha-chain mutant.

In the chromatogram obtained using the VARIANT ${ }^{\mathrm{TM}}$ system, $\mathrm{Hb} \mathrm{VM}$ migrated as described by Ma et al. (2004) and it was possible to detect the presence of Hb VM2. In the chromatogram obtained using the Ultra2 Resolution system, the pattern was identical to the standard provided by Trinity Biotech in their $\mathrm{Hb}$ variant library. The electrophoretic and chromatographic results allowed us to confirm the presence of $\mathrm{Hb} \mathrm{VM}$ and $\mathrm{Hb} \mathrm{VM} 2$ subfractions in the sample under study.

Table 2 summarizes the observations described in the papers mentioned above according to the tests used to diagnose Hb VM. 
Table 2. Parameters observed in studies that described the presence of $\mathrm{Hb}$ VM.

\begin{tabular}{|c|c|c|c|c|c|c|c|}
\hline $\begin{array}{l}\text { References } \\
\end{array}$ & Subject & Local & IEF & \begin{tabular}{|l|l} 
Alkaline electrophoresis \\
\end{tabular} & Acidic electrophoresis & Polypeptide chain electrophoresis & \begin{tabular}{|l} 
Percentage of $\mathrm{Hb}$ variant \\
\end{tabular} \\
\hline Wajcman et al. (1993) & 39-year-old man & \begin{tabular}{|l} 
Val de Marne (France) \\
\end{tabular} & $\begin{array}{l}\text { Slow moving } \\
\text { below } \mathrm{HbA}\end{array}$ & $\begin{array}{l}\text { Migrated as two bands } \\
\text { below } \mathrm{Hb} \mathrm{A}\end{array}$ & Slow moving below $\mathrm{Hb} \mathrm{A}$ & Abnormal alpha-globin band & $16.0 \% \%^{1 *}$ \\
\hline $\begin{array}{l}\text { Owen and Hendy (1994) } \\
\text { (1) }\end{array}$ & 27-year-old man & \begin{tabular}{|l|} 
Footscray (Australia) \\
\end{tabular} & 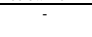 & $\begin{array}{l}\text { Migrated as two bands } \\
\text { in the } \mathrm{Hb} F \text { position }\end{array}$ & - & Abnormal alpha-globin band & $15.0 \%^{\mathrm{II}}$ \\
\hline \multirow[t]{2}{*}{ Ma et al. (2004) } & 15 -year-old girl ${ }^{2}$ & China & - & $\begin{array}{l}\text { Migrated as two bands } \\
\text { in the } \mathrm{Hb} F \text { position }\end{array}$ & Just one band: $\mathrm{Hb} \mathrm{A}$ & Abnormal alpha-globin band & $14.4 \%^{\mathrm{III}}$ \\
\hline & 61-year-old man $^{3}$ & China & - & $\begin{array}{l}\text { Migrated as two bands } \\
\text { in the } \mathrm{Hb} \mathrm{F} \text { position } \\
\end{array}$ & Just one band: $\mathrm{Hb} \mathrm{A}$ & Abnormal alpha-globin band & $16.0 \% \%^{\text {III* }}$ \\
\hline $\begin{array}{l}\text { Akbari and Hamid (2012) } \\
\end{array}$ & 26-year-old man & Iran & - & & & & $35.9 \%^{11}$ \\
\hline Present study & 32-year-old woman & Maringá (Brazil) & - & $\begin{array}{l}\text { Migrated as one band } \\
\text { below } \mathrm{Hb} \mathrm{A}\end{array}$ & $\begin{array}{l}\text { Migrated as one band } \\
\text { below } \mathrm{Hb} \mathrm{A}\end{array}$ & Abnormal alpha-globin band & $\begin{array}{l}14.7 \%(\mathrm{Hb} V \mathrm{VM}) \text { and } 0.9 \%(\mathrm{Hb} V \mathrm{VM} 2)^{\mathrm{IV}} \\
13.4 \%(\mathrm{Hb} \mathrm{VM}) \text { and } 0.6 \%(\mathrm{Hb} V \mathrm{MM} 2)^{\mathrm{V}}\end{array}$ \\
\hline
\end{tabular}

${ }^{a}$ Daughter and father; *retention time not reported; ${ }^{\mathrm{I}}$ quantification performed by ion-exchange high-performance liquid chromatography (HPLC); "percentage determined by scanning the cleared cellulose acetate plate on a Beckman Model R-112 densitometer; ${ }^{\mathrm{III}}$ quantification performed by HPLC on a VARIANT II ${ }^{\mathrm{TM}} \mathrm{Hb}$ Testing System (Bio-Rad Laboratories, Hercules, CA, USA) using the Beta-Thalassemia Short Program; ${ }^{\text {IV }}$ quantification performed by HPLC on a VARIANT ${ }^{\mathrm{TM}}$ Hb Testing System (Bio-Rad Laboratories) using the Beta-Thalassemia Short Program; ${ }^{\mathrm{v}}$ quantification performed by HPLC on an Ultra2 Resolution (Trinity Biotech, Wicklow, Ireland) with a Genesys assay kit.

For the identification of $\mathrm{Hb}$ variants, especially those with alteration alpha-chains, the use of several tests that are complementary to traditional $\mathrm{Hb}$ electrophoresis is necessary. This is important because several $\mathrm{Hb}$ variants called $\mathrm{S}$-like variants exist with similar electrophoretic mobilities to $\mathrm{Hb} \mathrm{S}$. In the case of $\mathrm{Hb} \mathrm{VM}$, the chromatogram obtained using the VARIANT $^{\mathrm{TM}}$ system suggested the possible presence of $\mathrm{Hb} \mathrm{S}$, but that was rejected because the concentration was below $15 \%$, and because of the presence of an alpha-chain mutation in the polypeptide chain electrophoresis. The standard verification by chromatogram performed using the Ultra2 Resolution system left no doubt about the variant being studied.

Few studies have reported the presence of $\mathrm{Hb} \mathrm{VM}$, but its detection in different locations such as France (Europe), Iran (Asia), Australia (Oceania), China (Asia), and now in Brazil (South America) suggests a dispersion of this $\mathrm{Hb}$ variant. Because $\mathrm{Hb} \mathrm{VM}$ brings no pathological consequences, patients do not seek medical care and thus remain undiagnosed.

Certainly, L.T.M.'s European ancestry contributed to her inheritance of $\mathrm{Hb} \mathrm{VM}$, taking into account the presence of $\mathrm{Hb} \mathrm{VM}$ in Italy and Ukraine. Both Italians and Ukrainians contributed to the ethnic composition of Brazil because both came to Brazil from 1870 onwards in search of employment in plantations, mainly in the South, to replace slave labor (Zamberlam, 2004).

The discovery of the $\mathrm{Hb} \mathrm{VM}$ variant in 1993 is recent. Therefore, little is known about the characteristics of $\mathrm{Hb}$ with regards to its hematological profile and the pattern it adopts in diagnostic tests for $\mathrm{Hb}$ variants. Thus, this study is important because it reports for the first time the $\mathrm{Hb} \mathrm{VM}$ variant in the Americas, and presents the results of electrophoretic and chromatographic procedures to facilitate the diagnosis of the $\mathrm{Hb}$ variant described.

\section{Conflicts of interest}

The authors declare no conflict of interest.

\section{ACKNOWLEDGMENTS}

We thank the technical teams of Laboratório de Hemoglobinas e Genética das Doenças Hematológicas and Laboratório de Ensino e Pesquisa em Análises Clínicas for supporting the analysis. 


\section{REFERENCES}

Akbari MT and Hamid M (2012). Identification of a-globin chain variants: a report from Iran. Arch. Iran Med. 15: 564567.

Clarke GM and Higgins TN (2000). Laboratory investigation of hemoglobinopathies and thalassemias: review and update. Clin. Chem. 46: 1284-1290.

Kimura EM, Oliveira DM, Jorge SE, Ribeiro DM, et al. (2015). Investigating alpha-globin structural variants: a retrospective review of 135,000 Brazilian individuals. Rev. Bras. Hematol. Hemoter. 37: 103-108. http://dx.doi. org/10.1016/j.bjhh.2015.01.005

Ma ES, Chan AY and Lee AC (2004). Molecular characterization of Hb Val de Marne [alpha133(H16)Ser $\rightarrow$ Arg; AGC $\rightarrow$ AGA; (alpha2)] in a Chinese family. Hemoglobin 28: 213-216. http://dx.doi.org/10.1081/HEM-120040306

Marengo-Rowe AJ (1965). Rapid electrophoresis and quantitation of haemoglobins on cellulose acetate. J. Clin. Pathol. 18: 790-792. http://dx.doi.org/10.1136/jcp.18.6.790

Owen MC and Hendy JG (1994). Hb Footscray or alpha 133(H16) Ser $\rightarrow$ Arg: a new hemoglobin variant. Hemoglobin 18: 19-27. http://dx.doi.org/10.3109/03630269409014142

Schneider RG (1974). Differentiation of electrophoretically similar hemoglobins-such as S, D, G, and P; or A2, C, E, and O--by electrophoresis of the globin chains. Clin. Chem. 20: 1111-1115.

Vella F (1968). Acid-agar gel electrophoresis of human hemoglobins. Am. J. Clin. Pathol. 49: 440-442.

Wajcman H, Kister J, M'Rad A, Marden MC, et al. (1993). Hb Val de Marne [alpha 133(H16)Ser $\rightarrow$ Arg]: a new hemoglobin variant with moderate increase in oxygen affinity. Hemoglobin 17: 407-417. http://dx.doi. org $/ 10.3109 / 03630269308997495$

Weatherall DJ and Clegg JB (2001). Inherited haemoglobin disorders: an increasing global health problem. Bull. World Health Organ. 79: 704-712.

Zamberlam J (2004). O processo migratório no Brasil e os desafios da mobilidade humana na globalização. Pallotti, Porto Alegre. 